\title{
Capacidade combinatória como critério de eficiência na seleção de genitores em feijoeiro(1)
}

\author{
Andreomar José Kurek ${ }^{(2)}$, Fernando Irajá Félix de Carvalho(2), Isidoro Carlos Assmann ${ }^{(3)}$ e Pedro Jacinto Cruz ${ }^{(4)}$
}

Resumo - Este trabalho teve por objetivo estimar a capacidade geral de combinação (CGC) e a capacidade específica de combinação (CEC) dos caracteres componentes do rendimento do feijoeiro (Phaseolus vulgaris L.), através de cruzamentos dialélicos entre seis genótipos utilizando o método 2 , modelo $\mathrm{B}$, proposto por Griffing. O experimento, em blocos completos casualizados, com quatro repetições, foi conduzido na safra de 1998, onde foram avaliados os seguintes caracteres: peso médio do grão; número de grãos/legume; número de legumes/planta, e rendimento. Os resultados da análise de variância evidenciaram maior importância da CGC em relação à CEC para todos os caracteres. Conforme a estimativa da CGC, o genitor Rudá foi o que apresentou, de modo geral, os melhores valores para os caracteres avaliados. Do mesmo modo, o maior efeito da CEC para os caracteres em geral foi obtido nos cruzamentos envolvendo os genitores Rudá x CI 967/2V, Rudá x FT Nobre e Pérola x CI 9661, determinando a importância desses genitores para os programas de melhoramento do feijão.

Termos para indexação: Phaseolus vulgaris, cruzamento dialélico, métodos de melhoramento.

\section{Combining ability as an efficiency criterion in the parental bean selection}

\begin{abstract}
The objective of the present work was to estimate the general combining ability (GCA) and specific combining ability (SCA) in the grain yield traits components through diallel cross of six bean (Phaseolus vulgaris L.) genotype using the method 2, model B, suggested by Griffing. The experiment was carried out in a complete randomized block design, with four replications, in 1998. The studied traits were: average weight grain; number of grain/pod; number of pod/plant and grain yield. The results of GCA evidenced more importance than SCA for all traits. According to the estimate of GCA, the parent Rudá showed the best values to the traits evaluated. In this way, the greater effect of SCA for the general traits were to get in wrapping up cross with parent Rudá x CI 967/2V, Rudá x FT Nobre and Pérola x CI 9661, determining the importance of these parents for the species improvement programs.
\end{abstract}

Index terms: Phaseolus vulgaris, diallel crossing, breeding methods.

\section{Introdução}

De origem americana, o feijoeiro é uma planta autógama cultivada com maior ou menor expressão

(1) Aceito para publicação em 24 de julho de 2000

(2) Universidade Federal de Pelotas (UFPel), Faculdade de Agronomia Eliseu Maciel (FAEM), Caixa Postal 354, CEP 96010-900 Pelotas, RS. Bolsista do CNPq E-mail: kurek@ufpel.tche.br, carvalho@ufpel.tche.br

(3) Centro Federal de Educação Tecnológica do Paraná, Unidade de Pato Branco, Caixa Postal 571, CEP 85503-390 Pato Branco, PR. E-mail: isidoro@cefetwhiteduck.com.br

(4) Universidade Federal do Rio Grande do Sul, Dep. de Genética e Biologia Molecular, Caixa Postal 776, CEP 90001-970 Porto Alegre, RS. Bolsista da Capes.

E-mail: jacinto@ufpel.tche.br em todos os estados do Brasil, sob diferentes condições de clima, solo e manejo. Conforme Vieira et al. (1999), o consumo per capita nacional é de $20,3 \mathrm{~kg} / \mathrm{ano}$. O rendimento médio da cultura é de $550 \mathrm{~kg} / \mathrm{ha}$, apesar de ser possível, em condições de cultivo com alta tecnologia, obter rendimento de grão superior a $3.000 \mathrm{~kg} / \mathrm{ha}$.

Em razão do baixo rendimento médio, caracteres como tipo do grão, arquitetura de planta, precocidade e resistência a pragas e moléstias têm recebido maior atenção dos programas de melhoramento genético da cultura, com o objetivo de aumentar a produção por área cultivada. Entre os mecanismos pelos quais se pode incrementar a produção da cultura numa região, a utilização de cultivares melhoradas é 
a única forma que não implica custos adicionais para o agricultor. Todavia, os programas de melhoramento têm revelado algumas deficiências sobre o conhecimento dos parâmetros genéticos responsáveis pelo caráter rendimento e seus componentes primários.

Deste modo, o sucesso do programa de melhoramento dependerá da eficiência na seleção dos genitores com a finalidade de serem utilizados em cruzamentos. Para o melhoramento genético de plantas é de fundamental importância a obtenção de informações sobre o potencial genético das cultivares, bem como sua capacidade de combinação, que resultem em híbridos produtores de populações segregantes promissoras.

Um dos métodos genético-estatísticos utilizados é o cruzamento dialélico. Suas aplicações foram amplamente discutidas e utilizadas por Jinks \& Haymann (1953), em trabalhos conduzidos com o milho. Vários métodos para análise e interpretação de cruzamentos dialélicos foram sugeridos (Haymann, 1954; Griffing, 1956; Gardner \& Eberhart, 1966). Em relação aos dialelos considerados, o método de Haymann (1954) estima principalmente variâncias e, portanto, suas informações são menos úteis para o melhorista de autógamas em comparação com os métodos de Griffing (1956) e de Gardner \& Eberhart (1966). Esses dois últimos se destacam por estimar componentes de média. O de Griffing (1956) fornece informações sobre as capacidades de combinação dos genitores em cruzamentos, e o de Gardner \& Eberhart (1966) faz um estudo detalhado da heterose.

Conforme Haymann (1954), várias hipóteses são relatadas de modo a atender à variabilidade do uso de dialelos, que em caso contrário, resultam em estimativas tendenciosas. Na cultura do feijoeiro, Ramalho et al. (1993) relatam que algumas restrições são, em geral, atendidas, como o uso de genitores homozigotos e segregação diplóide. Ao contrário de outras restrições, tais como a distribuição independente dos genes nos genitores e ausência de epistasia.

De acordo com Miranda Filho \& Geraldi (1984), o uso de cruzamentos dialélicos muitas vezes é limitado em virtude do grande número de cruzamentos necessários para avaliar um determinado número de cultivares. Nem sempre existe interesse na avaliação de todas as possíveis combinações através de um dialelo completo, principalmente diante da dificuldade de obtenção de número suficiente de sementes híbridas em certas espécies (aveia, feijão).

Sendo assim, o uso de dialélico balanceado incompleto envolvendo os genitores e apenas uma amostra dos cruzamentos possíveis $\left(\mathrm{F}_{1}\right)$ difere do dialélico completo pelo número de cruzamentos realizados entre os genitores. Para o dialélico completo temos $\mathrm{n}^{2}$ combinações dos pais, ou seja, genitores, híbridos simples e híbridos simples recíprocos. Usando apenas uma amostra dos cruzamentos sem os recíprocos, teremos $n(n-1) / 2$ combinações e assim não podemos considerar como sendo um dialélico completo, pois serão utilizados apenas $\mathrm{F}_{1}$ e genitores. Para Cruz \& Regazzi (1997), cruzamento dialélico incompleto é aquele em que ocorre a perda de tratamentos durante a combinação do ensaio ou ausência por insuficiência de sementes.

Este trabalho foi realizado para determinar os valores da capacidade geral de combinação (CGC) e capacidade específica de combinação (CEC) por meio do uso de cruzamentos dialélicos, visando auxiliar na seleção de genitores.

\section{Material e Métodos}

O experimento foi conduzido na safra agrícola de 1998 na estação experimental do Instituto Agronômico do Paraná, situada na cidade de Pato Branco, PR, com altitude aproximada de $700 \mathrm{~m}$ e precipitação pluvial de $1.800 \mathrm{~mm}$ distribuídas ao longo do ano. A implantação do experimento ocorreu no sistema de semeadura direta na primeira quinzena de outubro. A adubação de base, de acordo com as necessidades indicadas na análise, foi realizada pela aplicação de $50 \mathrm{~kg} /$ ha de $\mathrm{P}_{2} \mathrm{O}_{5} ; 40 \mathrm{~kg} / \mathrm{ha}$ de $\mathrm{KCl}$ e $40 \mathrm{~kg} / \mathrm{ha} \mathrm{de} \mathrm{N}$, sendo $20 \mathrm{~kg}$ de $\mathrm{N}$ aplicados na semeadura e o restante em cobertura, no 20 으 dia após a emergência. Para o controle de plantas invasoras, realizou-se uma capina, e para o controle de insetos foi utilizado o inseticida Metamidafós (Tamaron), na dosagem de $200 \mathrm{~mL} / \mathrm{ha}$.

Foram utilizados todos os 15 possíveis híbridos $\mathrm{F}_{1}$ sem considerar seus recíprocos e seis genitores de feijão, sendo Rudá, Pérola e CI 9661 do grupo carioca, e CI 967/2V, IAPAR 44 e FT Nobre, feijão preto. As cultivares foram escolhidas com base no rendimento e sua utilização agrícola; no caso das duas linhagens (CI 9661 e CI 967/2V) foram considerados os dados de ensaios preliminares.

Os $15 \mathrm{~F}_{1}$ e os seis genitores foram avaliados em delineamento experimental de blocos completos casualizados, 
com quatro repetições. Cada unidade experimental continha 10 plantas cultivadas em duas linhas de $1 \mathrm{~m}$ de comprimento com espaçamento de $0,45 \mathrm{~cm}$ entre linhas, e foram avaliados os seguintes caracteres: rendimento em $\mathrm{g} /$ parcela, peso médio do grão, número de grãos/legume e número de legumes/planta. A mensuração de dados para os 21 tratamentos foi realizada individualmente para todas as plantas de cada parcela, nas quatro repetições, sendo primeiramente contado o número de legumes/planta e, em seguida, realizada a debulha manual para contagem do número de grãos/legume. Posteriormente, os grãos foram pesados e obtidos o peso médio do grão e rendimento em $\mathrm{g} /$ parcela.

As análises estatísticas e dialélicas foram realizadas para cada carácter usando o programa computacional GENES, desenvolvido pela Universidade Federal de Viçosa, UFV (Cruz, 1997).

Para análise dialélica foi utilizado o método 2, modelo B, definido por Griffing (1956). O efeito de tratamento foi considerado como fixo e decomposto em capacidade geral de combinação (CGC) e capacidade específica de combinação (CEC). Neste caso, foi utilizado o seguinte modelo estatístico:

$$
\mathrm{Y}_{\mathrm{ij}}=\mathrm{m}+\mathrm{g}_{\mathrm{i}}+\mathrm{g}_{\mathrm{j}}+\mathrm{s}_{\mathrm{ij}}+\varepsilon_{\mathrm{ij}}
$$

onde

$\mathrm{Y}_{\mathrm{ij}}$ : valor médio da combinação híbrida $(\mathrm{i} \neq \mathrm{j})$ ou do genitor $(i=j)$;

m: média geral;

$\mathrm{g}_{\mathrm{i}} ; \mathrm{g}_{\mathrm{j}}$ : efeitos da CGC do i-ésimo e do j-ésimo genitor, respectivamente;

$\mathrm{s}_{\mathrm{ij}}$ : efeito da CEC para os cruzamentos entre os genitores $\mathrm{i}$ $\mathrm{ej}$;

$\varepsilon_{\mathrm{ij}}$ : erro experimental médio.

\section{Resultados e Discussão}

A análise de variância evidenciou diferenças significativas, pelo teste $\mathrm{F}$, a $1 \%$ de probabilidade, no quadrado médio de tratamentos, em todos os caracteres (Tabela 1). Desse modo, foi desdobrada a soma de quadrados de tratamentos em soma de quadrados para CGC e CEC, de acordo com o método 2, modelo B, de Griffing (1956).

Os quadrados médios referentes a CGC e CEC foram altamente significativos para todos os caracteres a $1 \%$ de probabilidade, exceto para a CEC do número de legumes/planta que não foi significativo (Tabela 1). Pela análise de variância, ficou evidenciada a existência da variabilidade genética aditiva e não-aditiva significativa entre as constituições genéticas avaliadas, através dos quadrados médios da CGC e CEC, respectivamente. Em todas as variáveis, a CGC foi maior do que a CEC, indicando uma maior participação da ação gênica aditiva no controle dos caracteres. A predominância da ação gênica aditiva no controle do rendimento de grãos e seus componentes primários foi também verificada por Santos et al. (1985) e Paniagua \& Pinchinat (1976). Nos programas de melhoramento, as seleções são praticadas em gerações segregantes avançadas visando à obtenção de um maior progresso genético, tendo em vista a ocorrência, nessas gerações, de diversas linhas puras na população com efeitos aditivos dos genes. Para Ramalho et al. (1993), esta é a razão pela qual a CGC é de maior importância para os melhoristas, uma vez que depende da variância aditiva.

Na Tabela 2 são apresentadas as médias originais, oriundas de quatro repetições, dos caracteres peso médio do grão, número de grãos/legume, número de legumes/planta e rendimento. A utilização das médias originais facilita a verificação dos melhores genitores antecipadamente à análise dialélica.

A seleção de genitores para representarem os blocos de cruzamentos é um aspecto de extrema importância nos programas de melhoramento, visto que será o ponto de partida para obtenção de novas cultivares. Conforme Miranda et al. (1988), são preferíveis os genitores com as mais altas CGC para constituírem as novas populações, favorecendo a seleção de linhagens homozigóticas, no caso de plantas autógamas.

De acordo com Cruz \& Regazzi (1997), a obtenção de uma estimativa para $g_{i}$, positiva ou negativa, muito baixa, indica que a CGC do genitor com base em seus cruzamentos não difere da média geral. Porém, quando as estimativas de $\mathrm{g}_{\mathrm{i}}$, positivas ou negativas, são elevadas, o genitor em questão é muito superior ou inferior aos demais genitores do dialelo.

No carácter rendimento, pode ser verificado, pelas estimativas dos efeitos da CGC, que somente os genitores Rudá, Pérola e FT Nobre apresentaram estimativas elevadas e positivas, o que indica uma possível contribuição no aumento do rendimento de grão. Entre os três genitores, o Pérola foi considerado superior, evidenciando seu maior potencial para incremento dessa característica e sugerindo sua utilização nos cruzamentos dos programas de melhora- 
Tabela 1. Análise de variância com os quadrados médios da capacidade geral de combinação (CGC), capacidade específica de combinação (CEC) e do resíduo, para quatro caracteres do feijoeiro segundo o modelo proposto por Griffing (1956). Pato Branco, PR, 1998.

\begin{tabular}{lrcccc}
\hline Fonte de variação & GL & \multicolumn{4}{c}{ Quadrado médio } \\
\cline { 3 - 6 } & & Peso médio do grão & Número de grãos/legume & Número de legumes/planta & Rendimento \\
\hline Tratamento & 20 & $0,00258^{* * *}$ & $0,337^{* *}$ & $54,829^{* *}$ & $9911,108^{* *}$ \\
CGC & 5 & $0,00959^{* *}$ & $0,550^{* *}$ & $122,929^{* *}$ & $26298,233^{* *}$ \\
CEC & 15 & $0,00022^{* *}$ & $0,265^{* *}$ & $32,136^{\text {ns }}$ & $4448,733^{* *}$ \\
Erro & 60 & 0,00008 & 0,089 & 15,216 & 1358,918 \\
\hline CV $(\%)$ & & 5,27 & 5,91 & 13,23 & 14,55 \\
\hline
\end{tabular}

ns Não-significativo. ${ }^{* *}$ Significativo a $1 \%$ de probabilidade pelo teste $\mathrm{F}$.

Tabela 2. Médias de peso médio do grão, número de grãos/legume, número de legumes/planta e rendimento de grãos em seis genitores e seus 15 híbridos em feijão. Pato Branco, PR, 1998.

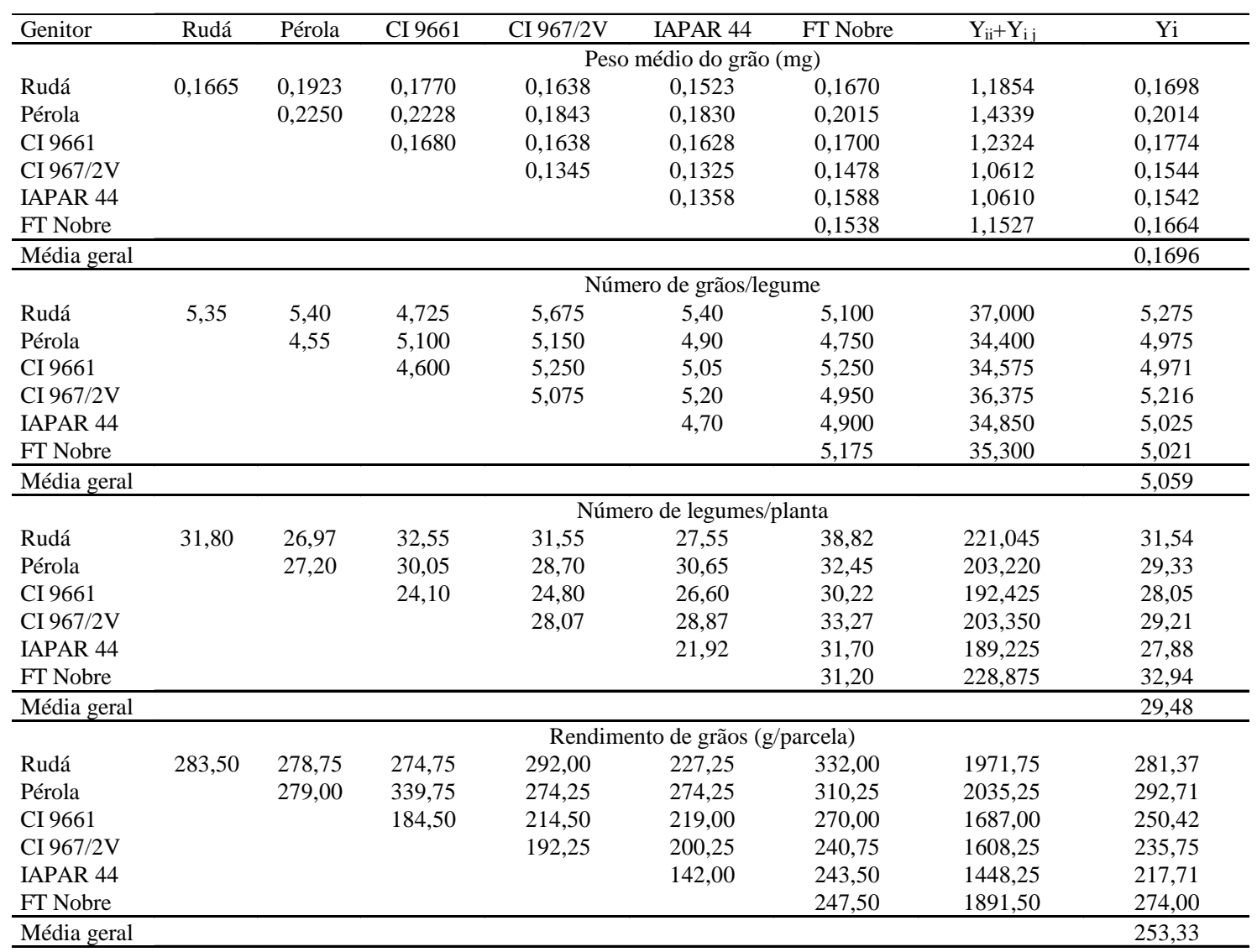

mento da cultura. É interessante observar que o FT Nobre apresentou estimativas da CGC negativas para peso médio do grão e número de grãos/legume, porém foi o que evidenciou o maior valor para número de legumes/planta, apontando, deste modo, a grande importância que representa o carácter número de legumes/planta para o rendimento final na cultura do feijoeiro.

Observando as estimativas da CGC, verifica-se que o genitor IAPAR 44 apresentou valores negativos e praticamente os mais elevados para todos os caracteres, indicando inferioridade em relação aos 
demais e sugerindo que sua utilização em cruzamentos provavelmente não resultará em progênies superiores.

Em relação a peso médio do grão, apenas os genitores Pérola e CI 9661 superaram a média geral (Tabela 2) e foram os únicos a apresentar valores positivos para CGC (Tabela 3), o que permite a indicação deles em cruzamentos com o objetivo de promover essa característica. Quanto a número de grãos/ legume, foi verificada maior contribuição dos genitores Rudá e CI 967/2V, sendo também os únicos a superarem a média geral (Tabela 2). No caráter número de legumes/planta, os melhores genitores de acordo com a CGC foram Rudá e FT Nobre, os quais superaram a média geral (Tabela 2).

O genitor Rudá foi o que evidenciou melhor CGC, estando sempre entre os melhores para número de grãos/legume, número de legumes/planta e rendimento com valores elevados e positivos, com exceção do peso médio do grão, que foi negativo, porém muito próximo a zero, indicando grande participação de todos esses caracteres no aumento do rendimento.

De acordo com Cruz \& Regazzi (1997), o efeito da CEC é interpretado como o desvio do híbrido em relação ao que seria esperado com base na CGC de seus genitores. Deste modo, baixos valores apresentados de $\mathrm{s}_{\mathrm{ij}}$ indicam que os híbridos apresentam um comportamento conforme o esperado com base nos valores da CGC, enquanto altos valores absolutos de $\mathrm{s}_{\mathrm{ij}}$ indicam um desempenho melhor ou pior do que o esperado. As estimativas de $\mathrm{s}_{\mathrm{ij}}$ evidenciam a importância dos genes com efeitos não-aditivos.

As estimativas $\mathrm{s}_{\mathrm{ii}}$ dos caracteres peso médio do grão, número de grãos/legume, número de legumes/ planta e rendimento (Tabela 4) foram todas elevadas e negativas, com exceção do genitor FT Nobre para número de grãos/legume, que apresentou sinal positivo, indicando que há grande divergência entre os genitores para todos os caracteres.

O maior efeito da CEC no rendimento foi observado nos híbridos Rudá x CI 967/2V, Rudá x FT Nobre e Pérola x CI 9661 (Tabela 4), sugerindo que o uso de seus genitores nos programas de melhoramento poderá gerar linhagens superiores e possíveis cultivares promissoras. Nos programas de melhoramento, $\mathrm{o}$ cruzamento Rudá x FT Nobre tende a ser mais promissor do que o cruzamento Rudá x CI 967/2V, pelo fato de o genitor FT Nobre possuir melhores caracteres agronômicos e de qualidade em relação ao CI 967/2V.

Os híbridos de Rudá x CI 967/2V, Pérola x CI 9661 e CI 9661 x IAPAR 44 foram os únicos com CEC positiva para todos os caracteres, apresentando valores de intermediário a superiores. Ainda sobre os híbridos, Rudá x CI 967/2V e Pérola x CI 9661 foram os que obtiveram praticamente as maiores CEC para todos os caracteres. Todavia, a princípio, o híbrido Pérola x CI 9661 possui caracteres indesejáveis, como a cor do halo. CI 9661 apresenta halo laranja, cujos genótipos com esse caráter não apresentam valor comercial. Já para o híbrido CI 9661 x IAPAR 44, a cor do halo não interfere na sua avaliação, pois apresenta tegumento escuro, o que anula o efeito da cor.

As estimativas da CEC para peso médio do grão indicam que os híbridos de valores mais elevados e positivos foram Rudá x CI 967/2V e Pérola x CI 9661. Os genitores Pérola e CI 9661 foram os únicos para esse caráter que apresentaram valores positivos também para CGC. Para número de grãos/legume, novamente os híbridos Rudá x CI 967/2V e Pérola x

Tabela 3. Valores da capacidade geral de combinação $\left(\mathrm{g}_{\mathrm{i}}\right)$, de quatro caracteres em seis genitores de feijão. Pato Branco, PR, 1998.

\begin{tabular}{lrrrrrrr}
\hline Caracteres & \multicolumn{3}{c}{ Capacidade geral de combinação } & \multicolumn{2}{c}{ Erro padrão } \\
\cline { 2 - 6 } & \multicolumn{1}{c}{ Rudá } & Pérola & CI 9661 & CI 967/2V & IAPAR 44 & FT Nobre & $\left(\mathrm{g}_{\mathrm{i}} \mathrm{g}_{\mathrm{j}}\right)$ \\
\hline Peso médio de grão & $-0,0003$ & 0,0307 & 0,0055 & $-0,0158$ & $-0,0158$ & $-0,0043$ & 0,0022 \\
Número de grãos/legume & 0,1979 & $-0,1270$ & $-0,1052$ & 0,1197 & $-0,0708$ & $-0,0145$ & 0,0708 \\
Número de legumes/planta & 1,8360 & $-0,3920$ & $-1,7414$ & $-0,3758$ & $-2,1414$ & 2,8147 & 0,9751 \\
Rendimento & 24,8020 & 32,7390 & $-10,7910$ & $-20,8850$ & $-40,6350$ & 14,7700 & 9,2158 \\
\hline
\end{tabular}


Tabela 4. Estimativa dos efeitos da capacidade específica de combinação para peso médio do grão, número de grãos/ legume, número de legumes/planta e rendimento de grãos resultante de um dialelo envolvendo seis genitores de feijão e seus 15 híbridos. Pato Branco, PR, 1998.

\begin{tabular}{lcccc}
\hline Genitor ou híbrido & Peso médio do grão & Número de grãos/legume & Número de legumes/planta & Rendimento \\
\hline Rudá & $-0,0026$ & $-0,1054$ & $-1,3516$ & $-19,4375$ \\
Pérola & $-0,0062$ & $-0,2554$ & $-1,4954$ & $-39,8125$ \\
CI 9661 & $-0,0128$ & $-0,2492$ & $-1,8967$ & $-47,2500$ \\
CI 967/2V & $-0,0035$ & $-0,2242$ & $-0,6529$ & $-19,3125$ \\
IAPAR 44 & $-0,0021$ & $-0,2179$ & $-3,2716$ & $-30,0625$ \\
FT Nobre & $-0,0071$ & 0,1446 & $-3,9092$ & $-35,3750$ \\
Rudá $\times$ Pérola & 0,0078 & 0,2696 & $-3,9535$ & $-32,1250$ \\
Rudá $\times$ CI 9661 & 0,0021 & $-0,4273$ & 2,9758 & 7,4062 \\
Rudá $\times$ CI 967/2V & 0,0103 & 0,2977 & 0,6102 & 34,7500 \\
Rudá $\times$ IAPAR 44 & $-0,0012$ & 0,2134 & $-1,6241$ & $-10,2500$ \\
Rudá $\times$ FT Nobre & 0,0020 & $-0,1429$ & 4,6946 & 39,0937 \\
Pérola $\times$ CI 9661 & 0,0168 & 0,2727 & 2,7040 & 64,4688 \\
Pérola $\times$ CI 967/2V & $-0,0003$ & 0,0977 & $-0,0116$ & 9,0625 \\
Pérola $\times$ IAPAR 44 & $-0,0016$ & 0,0384 & 3,7040 & 28,8125 \\
Pérola $\times$ FT Nobre & 0,0055 & $-0,1679$ & 0,5477 & 9,4062 \\
CI 9661 × CI 967/2V & 0,0044 & 0,1758 & $-2,5623$ & $-7,1562$ \\
CI 9661 $\times$ IAPAR 44 & 0,0034 & 0,1665 & 1,0031 & 17,0937 \\
CI 9661 $\times$ FT Nobre & $-0,0008$ & 0,3102 & $-0,3279$ & 12,6875 \\
CI 967/2V $\times$ IAPAR 44 & $-0,0055$ & 0,0915 & 1,9127 & 8,4375 \\
CI 967/2V $\times$ FT Nobre & $-0,0016$ & $-0,2148$ & 1,3565 & $-6,4688$ \\
IAPAR 44 $\times$ FT Nobre & 0,0094 & $-0,0742$ & 1,5471 & 16,0312 \\
\hline
\end{tabular}

CI 9661 juntamente com CI 9661 x FT Nobre foram os que apresentaram as melhores estimativas para CEC. Para número de legumes/planta, os cruzamentos Rudá x FT Nobre e Pérola x IAPAR 44 revelaram os maiores valores.

Constata-se que os cruzamentos Rudá $x$ CI 967/2V e Pérola x CI 9661 praticamente apresentaram sempre as melhores estimativas da CEC para os caracteres avaliados, indicando grande probabilidade de se obter genótipos superiores utilizando-os nos cruzamentos artificiais.

\section{Conclusões}

1. O genitor Rudá expressa considerável capacidade geral e específica de combinação, de modo que é recomendada sua utilização nos programas de melhoramento genético.

2. O genitor IAPAR 44 não evidencia valores expressivos para ser utilizado em cruzamentos de feijão por possuir baixa capacidade de combinação para os genótipos e caracteres considerados.
3. A eficiência da seleção nos caracteres estudados tem suporte na ação gênica de aditividade e proporciona progressos específicos no melhoramento do feijoeiro.

\section{Referências}

CRUZ, C. D. Aplicativo computacional em genética e estatística. Viçosa : UFV, 1997. 442 p.

CRUZ, C. D.; REGAZZI, A. J. Modelos biométricos aplicados ao melhoramento genético. Viçosa : UFV, 1997. $390 \mathrm{p}$.

GARDNER, C. O.; EBERHART, S. A. Analysis and interpretation of the variety cross diallel and related populations. Biometrics, Washington, v. 22, p. 439-452, 1966.

GRIFFING, B. Concept of general and specific combining ability in relation to diallel crossing systems. Australian Journal of Biological Sciences, Collingwood, v. 9, p. 463-493, 1956.

HAYMANN, B. I. The theory and analysis of diallel crosses. Genetics, Bethesda, v. 39, p. 789-809, 1954. 
JINKS, J. L.; HAYMANN, B. I. The analysis of diallel crosses. Maize Genetics Cooperation Newsletter, Columbia, v. 27, p. 48-54, 1953.

MIRANDA, J. E. C. de; COSTA, C. P. da; CRUZ, C. D.

Análise dialélica em pimentão. I. Capacidade combinatória.

Revista Brasileira de Genética, Ribeirão Preto, v. 11, p. 431-440, 1988.

MIRANDA FILHO, J. B.; GERALDI, I. O. An adapted model for the analysis of partial diallel crosses. Revista Brasileira de Genética, Ribeirão Preto, v. 7, p. 677-688, 1984.

PANIAGUA, C. V.; PINCHINAT, A. M. Criterios de selección para mejorar el rendimiento de grano en fríjol
(Phaseolus vulgaris L.). Turrialba, San José, v. 26, n. 2, p. 126-131, 1976.

RAMALHO, M. A. P.; SANTOS, J. P. dos; ZIMMERMANN, M. J. de O. Aplicacões ao melhoramento do feijoeiro. Goiânia : Ed. da UFG, 1993. 271 p.

SANTOS, J. B.; VENCOVSKY, R.; RAMALHO, M. A. P. Controle genético da produção de grãos e de seus componentes primários em feijoeiro. Pesquisa Agropecuária Brasileira, Brasília, v. 20, n. 10, p. 12031211, out. 1985 .

VIEIRA, C.; BORÉM, A.; RAMALHO, M. A. P. Melhoramento do feijão. In: BORÉM, A. Melhoramento de espécies cultivadas. Viçosa : UFV, 1999. p. 273-349. 